\title{
CORPO E CULTURA: cartografias da contemporaneidade
}

\author{
BODY AND CULTURE: cartography of contemporary
}

Lionês Araújo dos Santos ${ }^{1}$

\section{RESUMO}

Este artigo procura situar o corpo na cultura contemporânea em relação às transformações sociais e culturais que vem ocorrendo nas últimas décadas. Destaca as mudanças na estrutura social da modernidade, as quais parece demonstrarem dar início a uma nova era, pós-moderna, o que possibilita novas configurações da sociedade contemporânea. Pensa-se o corpo, a subjetividade, a evidência e veiculação de um ideal de corpo e de beleza na mídia, a relação com o mercado e o consumo nos dias atuais.

Palavras-chave: Corpo. Cultura. Contemporaneidade. Consumo.

\section{ABSTRACT}

This article seeks to situate the body in contemporary culture in relation to social and cultural transformations that have occurred in recent decades. Highlights the changes in the social structure of modernity, which seems to demonstrate initiation of a new postmodern age which allows new configurations of contemporary society. It is thought the body, subjectivity, evidence and propagation of an ideal body and beauty in the media, the relationship with the market and consumption today. Keywords: Body. Culture. Contemporary. Consumption.

\section{INTRODUÇÃO}

Hoje é comum dizermos que o homem enfrenta novas forças: o silício e não mais simplesmente o carbono, o cosmo e não mais o mundo...

[Gilles Deleuze]

O corpo é hoje um desafio político importante, é o analista fundamental de nossas sociedades contemporâneas.

[David Lê Breton]

\footnotetext{
${ }^{1}$ Mestre em Estudos de Cultura Contemporânea pelo ECCO/UFMT, graduado em Filosofia/UFMT, Professor efetivo da Rede Estadual de Educação Básica/SEDUC/MT e, atualmente, graduando do Curso de História da Universidade Federal de Mato Grosso. lionessantos@hotmail.com
}

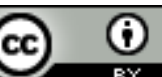

Esta obra foi licenciada com uma Licença Creative Commons - Atribuição 3.0 Não Adaptada. 
Ao longo da história, vários foram os paradigmas ${ }^{2}$ que já se lançaram na tentativa de interpretação das sociedades. A religião, a política, a economia, a cultura, a comunicação e, mais recentemente, o consumo. Todas essas instâncias ou fenômenos, em algum momento ocuparam espaço privilegiado na mente e nos escritos de vários teóricos e intérpretes da sociedade e da cultura. Posto isso, talvez, podemos dizer que as ciências humanas são ciências "paradigmáticas" por excelência e, na tentativa da compreensão do humano, estão sempre em crise nos seus modelos teóricos.

Certamente, a modernidade ${ }^{3}$ foi um dos períodos mais férteis da história na concepção de grandes empreendimentos teóricos na tentativa de compreensão da sociedade e da cultura. O mundo moderno concebeu "audaciosos" projetos e lançou grandes ideologias. Apoiado na idéia de progresso, nos pressupostos da universalidade, do individualismo e da autonomia do pensamento, o mundo da modernidade projetou-se como um período em que as condições para o esclarecimento eram evidentes, bastando lançar mão do exercício da liberdade ${ }^{4}$

. Dessa forma, não havia tanto espaço para a dúvida ${ }^{5}$ nem para as incertezas e as narrativas pareciam ser insuperáveis. Hoje, no entanto, um sistema filosófico dá lugar a outro, uma teoria científica substitui outra e não temos mais como saber qual sistema é mais coerente e qual teoria é a mais verdadeira. Dessa forma, as metas narrativas - tão caras à modernidade - não são mais acreditadas como fio condutor dos anseios humanos. A pós-modernidade desencadeou questionamentos sobre o projeto moderno e suas aspirações. Assim, novos paradigmas são postos e

\footnotetext{
${ }^{2}$ Segundo Thomas Khun, "paradigmas" são "as realizações científicas universalmente reconhecidas que, durante algum tempo, fornecem problemas e soluções modelares para uma comunidade de praticantes de uma ciência". Ver: KHUN, Thomas. A estrutura das revoluções científicas. 4 ed. Tradução de Beatriz Vianna Boeira e Nelson Boeira. São Paulo, SP: Editora Perspectiva, 1996. p. 13.

${ }^{3} \mathrm{O}$ conceito de modernidade, apesar de ter sido tomado como premissa inicial do debate, não será aqui aprofundada, pois não constitui foco principal da pesquisa e, vale lembrar que as terminologias acerca do mundo hodierno não são consenso. Inúmeras são as terminologias que, de alguma forma, tocam a questão. Fala-se em: modernidade líquida, modernidade tardia, modernidade reflexiva, pósmodernidade, pós-modernização, hiper-modernidade, etc.

${ }^{4} \mathrm{Na}$ resposta à pergunta: "O que é Esclarecimento"? (Aufklãrung), o filósofo Immanuel Kant (1985) nos diz que as condições para o esclarecimento e para a autonomia poderiam ser dadas pelo que chamou de Sapere aude! (ouse saber! - lema do esclarecimento). Kant argumenta que o esclarecimento "é a saída do homem de sua menoridade, da qual ele próprio é culpado", bastando para isso, fazer uso da razão e "ousar saber".

5 É importante lembrar que, no século XVII o filósofo René Descartes (1998), um dos principais fundadores da modernidade, pôs a prova todas as certezas religiosas e, ao fazer isso, Descartes chegou ao conceito do "cogito ergo sum" (penso, logo existo). A partir daí, as incertezas poderiam ser superadas pelo uso do método correto na condução da razão. Na sua obra seminal: Discurso do Método, Descartes trata do método de como conduzir bem a razão e buscar a verdade no domínio das ciências.
} 
juntamente, a necessidade de outras narrativas, diferentes e, até por vezes, contrastantes com àquelas da modernidade.

Muitos dos autores aqui elencados que teorizam sobre a contemporaneidade, como por exemplo, Serres (1992; 2003), Bauman (1999; 2001; 2007), Lipovetsky (1989; 2005), Klein (2006), Canclini (1995), Hall (2003), Sibilia (2002), Costa (2001; 2005), dentre outros, parecem ser quase unânimes em descrever a pósmodernidade como um fenômeno emergente que evidencia certa ruptura com os modelos tradicionais antes acreditados. A idéia de universalidade, progresso, liberdade, objetividade, unidade, verdade, razão e autonomia do pensamento; que antes parecia tão evidente deu lugar a conceitos recorrentes de fragmentação, incerteza, dispersão, efemeridade, desterritorialização, mestiçagens e subjetividades. É também importante ressaltar que estes autores são unânimes em atribuir grande força à publicidade e ao surgimento de uma cultura do consumo como característica da sociedade contemporânea.

Retomo aqui um conceito que parece nos remeter as transformações que vem ocorrendo na contemporaneidade: a idéia de pós-modernidade. François Lyotard (1989) nos traz a idéia de que, na pós-modernidade, os grandes sistemas teóricos legitimados, as verdades construídas pelos autores da modernidade ruíram. Na pós-modernidade, um sistema de pensamento surge a cada momento, substitui outro, cria um novo paradigma e, dessa forma, não temos como saber qual é o mais verdadeiro. Talvez a melhor decisão a tomar seja partir da idéia de que em matéria de conhecimento, somos todos produtores e ao mesmo tempo produtos de narrativas, de discursos e de possibilidades.

Antes, até a modernidade, as instâncias tradicionais como: família, religião, trabalho, nacionalidade e ideologia, eram as principais "doadoras" de identidade. $\mathrm{Na}$ pós-modernidade, parece haver certo enfraquecimento dessas instâncias mestras, onde elas próprias não só deixaram de doar identidade e dar sentido a vida, como parecem perder o sentido, ou seja, a sua identidade tradicional a cada dia $^{6}$. As

\footnotetext{
${ }^{6}$ É importante lembrar que a idéia de família que temos hoje é completamente diferente da que tínhamos há algumas décadas atrás. Hoje, as famílias são cada vez mais "pluri-parentais", desprovidas de um núcleo específico. Atualmente, por exemplo, além dos tradicionais pais biológicos, entram também em cena da paternidade; padrastos, provedores, integrantes de uma união afetiva que pode ser formada tanto por casais heteros quanto por pessoas do mesmo sexo. Em condições semelhantes encontra-se também a religião. Hoje, muitas pessoas podem professar a fé católica, por exemplo, e, ao mesmo tempo freqüentar cultos evangélicos, sessões espíritas ou templos budistas. Da mesma forma a questão do trabalho e da ideologia. A carteira de trabalho e o conceito de profissão cada vez mais cedem à volatilidade do mercado e das relações sociais.
} 
hierarquias antes estabelecidas e as fronteiras rígidas de classes e de gêneros se diluem cada vez mais no tecido social que se torna matizado e plural.

Atualmente, por exemplo, o fato de alguém ser judeu, africano, latino, socialista, capitalista, burguês, operário, católico, protestante, budista, hinduísta, ateu, agnóstico ou ainda, pertencer à determinada família - tida por tradicional, pelo menos na cultura ocidental - já não faz tanto sentido como antes. No mundo globalizado, com os avanços tecnológicos acelerados, a flexibilização das relações e a reinvenção do capitalismo, essas definições já não são tão importantes. Um cartão de crédito fornecido por uma empresa que opera mundialmente os unifica e, ao mesmo tempo, particulariza o sentido de ser e de existir de cada pessoa.

Presumo que, nestes dias, a única instância com caráter de universalidade que parece encontrar um ponto comum no pensamento de vários dos autores, teóricos da pós-modernidade que consultei, é o fenômeno do mercado e do consumo. Todos os habitantes do planeta, de uma forma ou de outra, estão submetidos ao consumo e ao mercado. O consumo hoje parece fornecer a identidade ao indivíduo, quem ele é e de quem ele se diferencia. Talvez, nesse aspecto, seja possível falar da idéia de uma diferenciação social, ou até mesmo, pensar a idéia da cidadania pela ótica do consumo. Mas uma coisa é certa: o consumo é global, em todas as culturas. Por isso mesmo, o consumo se tornou nos últimos anos um dos paradigmas sobre o qual se lançam diversos olhares, atraindo vários campos do saber.

\section{DO OBJETO EM QUESTÃO: CORPO E CULTURA NA CONTEMPORANEIDADE}

Ao lado do fenômeno do consumo, o corpo parece despontar-se, nas últimas décadas, como um novo paradigma emergente na contemporaneidade, sobre o qual, vários olhares começam a ser lançados. Em meio a esse caldo de cultura, o corpo entra em cena como objeto de possibilidades.

O objeto posto em questão nessa discussão é, portanto, a relação do corpo com a cultura contemporânea, sua evidência e possibilidades de subjetivação através de discursos e práticas. O objetivo aqui não é o de esgotar a questão ao apresentar impasses da temática ou de definir o objeto corpo a partir de um único 
marco teórico. Trata-se mais de fazer certos apanhados bibliográficos de diferentes referenciais teóricos, que, de alguma forma, apresentam pontos comuns capaz de dialogarem sobre as várias possibilidades de pensar o corpo na cultura contemporânea. De todo modo, o que esse trabalho propõe é uma espécie de "cartografias do contemporâneo" a respeito do corpo e da cultura.

A partir de marcos teóricos contemporâneos, pertencentes aos diversos campos de conhecimento é possível, com bastante evidência, identificar uma valorização extrema do corpo no pensamento contemporâneo. A forma como o corpo é explorado pela mídia e por diversas vertentes do saber já revela o caráter abrangente dessa questão. A antropologia, a sociologia, a comunicação, a psicanálise, as artes, a linguagem; são exemplos de áreas que encontram no corpo, seu mais novo e fértil objeto de estudo e campo de investigação privilegiado. É a partir dessa complexa realidade social e análises epistemológicas sobre os modos de "fazer" e de pensar o corpo contemporâneo que partem as investigações e análises propostas nesse artigo.

O objetivo é, portanto, apresentar alguns traços comuns no pensamento de teóricos da contemporaneidade que, de algum modo, ao pensarem o nosso tempo acabam de certa forma por trazerem a tona questões que colocam o corpo em evidência, seja via consumo por meio da moda ou através de modificações estéticas de sua estrutura natural.

A estratégia teórica metodológica para abordagem da questão do corpo na cultura contemporânea não consiste aqui numa delimitação de campos ou correntes teóricas específicas. O recorte consiste antes na eleição de uma bibliografia atualizada com a contemporaneidade, em que as abordagens sobre as relações da sociedade contemporânea com o corpo ganham centralidade.

Portanto, todos os autores aqui elencados têm sua produção marcada por certa tentativa de descrever aspectos característicos de uma época que, mesmo se apresentando em grande parte como fugidia, ao menos alguns elementos que o caracterizam talvez seja possível identificar, como por exemplo, uma evidência e exposição do corpo talvez nunca antes presenciada e que tem despertado o interesse de diversos saberes. 


\section{CORPO E SUBJETIVIDADE NA CONTEMPORANEIDADE}

Hoje o corpo parece ser o resultado da subjetividade dominante, a qual é atravessada por fatores biológicos, econômicos, sociais, culturais e midiáticos. Félix Gattari (2000, p. 278), parece ter identificado a lógica dos diversos agenciamentos que perpassam o corpo em diferentes épocas. Segundo Gattari, o corpo submete ao "[...] tipo de funcionamento de economia doméstica, de economia social". Assim, posso dizer que, o corpo, hoje, talvez seja uma representação bastante plausível dessa nossa época onde a comunicação e o mercado têm um papel central na vida e nas relações humanas.

Vários campos de estudo estão sendo, de alguma forma, tomados pelo surgimento das "bio-identidades", onde os referenciais do corpo e da biologia, ancorados na ciência médica, assumem papel central. O corpo parece ter sido tomado por um processo "bio-ascético" do "cuidado de si". Ele deixou de ser um meio para se tornar um fim em si mesmo. Tudo aquilo que o pensamento metafísico e religioso recriminou durante um longo período de tempo, considerando desprovido de valores nobres, proibido e pecaminoso; expressa agora no corpo contemporâneo. A meu ver, está ocorrendo um processo de inversão, onde a alma parece estar saindo do jogo, enquanto o corpo entra em cena passando a ser mais exposto, valorizado, aplaudido e cultuado.

Geralmente, a valorização de uma coisa acontece em detrimento de outra. Quando, por exemplo, a metafísica entra em crise, ressurgem com vigor valores opostos aos ideais supremos do pensamento abstrato. Suponho que esse processo de extrema valorização da corporeidade e da materialidade do corpo seja o reflexo da crise da alma, da razão e do pensamento. Jurandir Freire Costa (2005, p. 84) é enfático ao antecipar que: "Se o corpo vem ofuscando o brilho da mente é porque vivemos em uma sociedade que perdeu a sua alma". Esse argumento parece fazer cada vez mais sentido.

A canção Alma, de Zélia Duncan, provavelmente dá algumas pistas destes tempos atuais, onde o "eu" interior se revela na exterioridade da pele: "Alma, deixa eu ver sua alma, na superfície da palma da minha mão [...] Alma, daqui do lado de fora nenhuma forma de trauma sobrevive", canta Zélia Duncan nos seus versos. Os sentimentos interiores exteriorizaram-se e eventos externos são transformados em 
acontecimentos internos. A vida psíquica passa a ser o resultado de um corpo esbelto, "sarado", de uma pele sem rugas, do corte de cabelo, da maquiagem, do vestuário, da marca do tênis etc. Assim, hei de concordar com a letra da canção de Zélia Duncan quando expressa que "[...] do lado de fora [...] nenhuma forma de trauma sobrevive". Qualquer sentimento de considerar-se feio, fora de forma, pode encontrar a solução nas compras, no salão de beleza, na academia de ginástica ou numa clínica de cirurgia plástica. Esses serviços se expandem a cada dia e já estão ao alcance de muitos. Mesmo daqueles com menor poder aquisitivo.

Acredito que se até mesmo a alma atualmente se expressa no corpo, é este, de fato, que deve ser tomado como objeto privilegiado de investigação. Já há algum tempo, as ciências da vida, a antropologia, a sociologia e até mesmo a comunicação parecem ter compreendido muito bem essa questão ${ }^{7}$. Hoje, todo e qualquer descontentamento no plano psicológico parece encontrar a solução no plano físico, na materialidade da pele ou nos genes. Um exemplo disso são as compulsões por cirurgias plásticas ${ }^{8}$.

No livro Em nome do corpo, os pesquisadores da UFRJ, Nízia Villaça e Fred Góes (1998, p. 30), escreveram que: "Quando fatores de organização das identidades sociais como nação, etnia e classe perdem crescentemente seu poder aglutinador, o corpo, suas expressões, envelopes e próteses propiciam análises mais singulares fora da ótica "macro" dos grandes sistemas classificatórios, e uma nova ordem se processa". Acredito que, atualmente, essa nova ordem se dá necessariamente no plano da "microfísica"9, do desejo, do sensível e do corpóreo. Passamos, assim, de uma cultura com valores interiores, do sentimento e da interioridade, para uma cultura exterior, da percepção e das sensações, onde a subjetividade passa a se apresentar no corpo, na exterioridade da pele. Assim, o que o indivíduo contemporâneo apresenta ser não é mais o que ele é na sua

\footnotetext{
${ }^{7}$ Tenho a impressão de que estamos cada vez mais deixando os problemas metafísicos de lado para dedicarmos mais de perto aos cuidados para com o mundo físico, em especial, o corpo. Atualmente, surgem vários programas de pesquisa com o objetivo de estudar os genes, a saúde, o corpo e suas funções orgânicas. Além disso, presenciamos, hoje, uma "biologização" do comportamento e de todas as diferenças manifestas, uma espécie de reducionismo do ser ao aspecto material em todas as suas dimensões. Tudo aquilo que escapa à ordem natural da genética é passível de correção, quiçá modificando a estrutura do próprio corpo.

${ }^{8} \mathrm{~A}$ rede de relacionamento social, Orkut, por exemplo, possui dezenas de comunidades com vários tópicos de discussões sobre cirurgias plásticas de toda natureza. Muitas delas possuem mais de 1.000 membros ativos em constante interação e troca de informações.

${ }^{9}$ Enquanto que no século passado se dedicava às grandes questões num plano "macro", hoje, todo tipo de operação parece tender a se passar no plano até mesmo inferior ao "micro". Falamos cada vez mais em "nanotecnologia", "nanorobôs", "nanomedicina", "nanopróteses", etc.
} 
interioridade, mas sim o que ele aparenta ser. O sujeito contemporâneo passou, no entanto, a ser aquilo que as marcas do seu corpo revelam. ${ }^{10}$

\section{O CORPO COMO ESPAÇO MULTIDISCIPLINAR}

Existem, portanto, várias perspectivas de discutir a questão do corpo hoje em dia. Posso dizer que, o corpo é, portanto, um espaço multidisciplinar, sobre o qual é possível lançar diferentes olhares dos diversos saberes e efetuar diversas práticas. Muitos estudiosos já debruçam sobre a emergência desse novo fenômeno que é o "corpo contemporâneo". Ocupam-se de interpretar, descrever e teorizar a crescente evidência do corpo nos dias atuais. Considero válido para enriquecer o debate, discorrer aqui sobre a tipologia levantada por David Le Breton (2009) em um dos seus trabalhos mais recentes sobre a questão, intitulado: $A$ sociologia do corpo. Le Breton faz um esboço teórico sobre as diversas tipologias elaboradas na epistemologia do corpo.

Dentre as principais vertentes de pesquisa sobre o corpo destacam-se àquelas sobre "os imaginários sociais do corpo". Dentro dessa abordagem, merecem consideração, especialmente, as correntes que privilegiam abordagens biológicas da corporeidade, onde todo o social parece ficar reduzido ao biológico. Talvez um dos principais representantes dessa corrente seja o famoso entomologista Eduardo Wilson com sua obra seminal, intitulada: Sociobiologia. Wilson procura explicar todo o social puramente pela ótica biológica ou genética ${ }^{11}$.

Dentro da vertente dos imaginários sociais do corpo merecem destaque ainda os trabalhos de Ervin Goffman (1988) sobre o que chamou de "estigma". Acredito que uma das contribuições mais importantes dos trabalhos de Goffman foi ajudar na

\footnotetext{
10 Tomo aqui como exemplo as tatuagens, a tintura dos cabelos, batons, bronzeadores, e, especialmente, a aplicação de botox (toxina botulínica) para rejuvenescimento facial. Atualmente, a carteira de identidade, pelo menos aparentemente, parece perder a função de revelar com veracidade a idade de uma pessoa.

${ }_{11}$ Essa forma de abordagem biológica do social e do corporal suscita inúmeras polemicas. Os defensores dessa abordagem acreditam, por exemplo, que os problemas sociais podem ser resolvidos através da construção de um código ético geneticamente correto. Por outro lado, correntes de pensamento contrárias a essa argumentação o consideram reducionista e perigoso. $O$ antropólogo David Le Breton (2009, p. 63), por exemplo, nos alerta de que: "Deixar a iniciativa da ética social aos genes e aos geneticistas não parece de fato nem um pouco prudente".
} 
compreensão da maneira como se dá a formação de estereótipos e ideais sociais representados pela publicidade, especialmente, quando se trata de hierarquizar e estabelecer divisões entre o sexo masculino e feminino. Enquanto o masculino aparece na publicidade como viril, provedor e protetor; o feminino, por sua vez, é representado como o "belo sexo", delicado, sensível, frágil e subalterno em relação ao masculino.

Outra vertente de pesquisas sobre o corpo que cada vez mais ganha espaço são os estudos sobre "as lógicas sociais e culturais do corpo". Esta vertente agrega vários campos de estudos sobre as diferentes lógicas que regem as relações dos indivíduos com seus corpos. O uso de técnicas, ritos, inscrições sobre a superfície da pele, pinturas, gestualidades e expressões corporais constituem objetos de estudos de interesse cada vez maior por parte de pesquisadores que se ocupam de desvendar as lógicas sociais e culturais do corpo. Essa vertente, segundo Le Breton (2009), parece ter sido inaugurada, especialmente, pelo sociólogo Marcelo Mauss e pelo antropólogo Levi-Strauss.

A outra vertente - talvez a que mais tem atraído atenção na contemporaneidade - é referente ao corpo no "espelho do social". Essa vertente é em partes a que constitui o eixo norteador deste trabalho. Nela, são analisados de forma mais aprofundada os fenômenos sociais contemporâneos que se relacionam com a corporeidade como: aparência, moda, consumo, grupos, classes sociais e controle político ou ideológico por meio do corpo. Dentre os fenômenos dessa vertente, a questão da aparência - ideal de beleza e perfeição - é um dos mais evidentes na exposição do corpo no espelho do social. Atualmente, este fenômeno já constitui um vasto império que alimenta vários segmentos da indústria e do comércio. $\mathrm{O}$ comércio de produtos de beleza e de combate ao envelhecimento movimenta milhões a cada ano.

Um mercado em pleno crescimento renova permanentemente as marcas
que visam à manutenção e à valorização da aparência sob os auspícios da
sedução ou da "comunicação". Roupas, cosméticos, práticas esportivas,
etc., formam uma constelação de produtos desejados destinados a fornecer
a "morada" na qual o ator social toma conta do que demonstra dele mesmo
como se fosse um cartão de visitas vivo (LE BRETON, 2009, p. 78).

Vestir-se na moda, ter estilo, alimentar-se bem, apresentar-se saudável, são alguns exemplos de discursos suscitados sobre a relação com o corpo. Talvez, como nunca antes na história, o corpo humano hoje se apresenta como suporte 
privilegiado de investimentos técnicos, econômicos e científicos, principal agente de práticas, significações e representações simbólicas. Sob essa ótica, o corpo se constitui na materialidade concreta a produzir seu reflexo no espelho social, sobre o qual se lança muitos olhares possíveis. Portanto, dentre as diferentes formas de se pensar a contemporaneidade, o corpo parece se apresentar, hoje, como uma das possibilidades privilegiadas.

\section{O MITO DO CORPO PERFEITO E IDEAL DE APARÊNCIA VEICULADO PELA MÍDIA}

Hoje, em pleno início do século XXI, nunca o corpo foi tão valorizado, exposto; nunca se falou tanto do corpo, nunca o corpo foi tão cultuado, tratado, "aperfeiçoado" e até, em certo sentido, supliciado na tentativa de obter a forma desejada. Instalou-se na sociedade contemporânea certa idéia de perfeição, um verdadeiro "mito do corpo perfeito". Esse mito, tal como uma espécie de vírus, se dissemina a cada dia pelas mentes, transpassando classes sociais, gêneros e etnias.

Uma vasta literatura de "auto-ajuda" dedicada ao corpo ocupa as estantes de bancas de revistas, jornais, e livrarias. Para citar um exemplo da expansão desse segmento informativo dedicado ao corpo, vejamos, por exemplo, o caso das publicações de revistas. É enorme a quantidade de títulos que surgiram nas últimas décadas. Farei aqui uma breve incursão acerca da disseminação dessa literatura informativa dedicada ao corpo. Vejamos: a partir dos anos 80 surgiram as duas primeiras publicações dedicadas à questão do corpo: as revistas Boa Forma e Belo Corpo. É importante lembrar que essas primeiras revistas nasceram da motivação dos discursos da "geração saúde", tratando inicialmente de qualidade de vida e ecologia. Somente posteriormente é que elas foram acrescentando novos conceitos em seus conteúdos e passaram a dar mais ênfase às questões como comportamento, sexo, moda e a noção de beleza, tão disseminadas hoje em dia. Parece ser bastante evidente que essas duas revistas, que antes se apoiavam na idéia de saúde e qualidade de vida, tenham se rendido a um determinado projeto de corpo, marcado pela aparência física e uma estética específica. 
Várias outras revistas de aconselhamento e informativos dedicados ao corpo, à beleza, à saúde e ao comportamento surgiram nas últimas três décadas. Dentre elas, algumas das principais são: Vida, Nova, Bons Fluidos, Saúde, Plástica e Beleza, Runners, Viva Saúde, Revista O Globo, Capricho e Cláudia. Embora essas duas últimas não sejam direcionadas a falar especificamente sobre o corpo, de alguma forma o fazem, ainda que secundariamente. A lista de publicações, dedicadas mais especificamente aos cuidados com o corpo, é enorme. $E$, constantemente, surgem outros lançamentos. Enumerá-las todas aqui não é minha intenção e nem consiste no objetivo central deste trabalho. Mencionei algumas, apenas como exemplo para ilustração da vasta literatura dedicada à corporeidade ${ }^{12}$ que se expande a cada dia.

Todos esses "arsenais" informativos disseminam idéias de que as pessoas não são bonitas o suficiente e é preciso cuidar da aparência e remodelar o próprio corpo. Atualmente, se uma pessoa é obesa, têm celulites, rugas, calvície, seios e bumbuns pequenos ou não está satisfeita com suas orelhas, com seu nariz ou dentes, não será pela carência de informações que ela deixará de ir buscar os meios necessários para a conquista da perfeição corporal apresentada pela mídia.

Muitas revistas trazem ainda uma infinidade de testes. Exemplos: "teste seu nível de colesterol", "teste se você está se alimentando da forma correta", "teste qual é sua expectativa de vida", "teste se você é romântica", "teste seu desempenho sexual" etc. Dicas de alimentação, dietas, programas de atividades físicas e anúncios de clínicas de cirurgias plásticas se propagam pelos mais diversos meios midiáticos. O ideal de perfeição corporal se dissemina e se apresenta como uma possibilidade de conquista que está ao alcance de todas as pessoas, de todas as classes, para todos os bolsos ${ }^{13}$. Com isso, ocorre que o corpo natural passa a ser num certo sentido, desqualificado, pois se apresenta como imperfeito passível de correções e que, portanto, não deve ser negligenciado. É preciso reinventar o próprio corpo, seja por meio de exercícios em academias de ginásticas, controle da alimentação, consumo de fármacos e anabolizantes ou por meio de intervenções

\footnotetext{
12 É importante lembrar também que, além da vasta literatura que surge a cada dia para discutir questões mais específicas relacionadas ao corpo, percebo que, boa parte do material informativo na atualidade como jornais e revistas de diversos segmentos, trazem, de alguma forma, matérias ligadas a questões de saúde, alimentação, beleza, sexo e comportamento, ou seja, matérias ligadas à corporeidade.

${ }^{13}$ Atualmente é possível realizar cirurgias plásticas em vários parcelamentos. Parcelamentos em 12 X, 18 X, 24 X, 36 X e até 48 vezes são oferecidas por clínicas cirúrgicas e de beleza estética.
} 
cirúrgicas, muitas vezes radicais, que chegam a deixar sequelas e, em casos mais esporádicos, levar a óbito.

Provavelmente, nunca antes na história humana, tantos e poderosos medicamentos e estratégias foram criados e desenvolvidos para atender as exigências de saúde, controle do comportamento e, conseqüentemente, do corpo. Para confirmar essa observação, basta folhear qualquer revista que aborde a questão da saúde ou do comportamento humano publicada mais recentemente. É bem provável que se depare com toda sorte de receitas de como se alimentar melhor, como praticar exercícios físicos da forma correta etc. Encontram-se os mais variados e mirabolantes programas de dietas, dicas de beleza, exercícios físicos e técnicas de rejuvenescimento.

Os anúncios publicitários estão sempre a fazer as pessoas infelizes. A estratégia principal é criar uma necessidade, um problema, para depois vender a solução. Uma pessoa, por exemplo, pode não ter nenhum problema em seu corpo, pode ter uma boa aparência física. Mas isso não importa. Os anúncios publicitários, de alguma forma, criam algum defeito. Observo, por exemplo, que as revistas que abordam questões sobre o corpo, a moda, a saúde e o comportamento disseminam idéias de que as pessoas não são bonitas o suficiente, de que não estão em forma e em bom condicionamento físico. A mídia cria a idéia de que é preciso adotar determinado estilo de se vestir para cada estação e cuidar permanentemente do corpo, da saúde e da beleza. Um corpo que é construído, uma saúde inventada e um padrão de beleza idealizado pelos discursos. Umas das primeiras conseqüências disso é que, para se manter segundo os padrões vigentes é preciso consumir, se render as compras. Pois, a moda muda a cada estação.

\section{CORPO E MERCADO}

$\mathrm{Na}$ sociedade atual, parece que as mulheres estão mais expostas ao consumo do que os homens, principalmente no que tange aos cuidados com o corpo e a aparência. Porém, essa situação está mudando cada vez mais. Aos poucos, os homens vão se equiparando às mulheres no exercício de vários papéis e, também, passam a adotar atitudes que antes pareciam estar reservadas somente às 
mulheres, como por exemplo: a preocupação com a aparência ${ }^{14}$ e com a saúde. Assim, acredito que, hoje, o mercado, com suas formas estratégicas, atingem por igual tanto mulheres quanto homens. Veja-se, por exemplo, anúncios veiculados numa revista masculina de nível mundial, como a Playboy, onde pode se encontrar uma modelo linda e um carro ou outra coisa e/ou produtos caros a serem adquiridos para se "conseguir" mulheres lindas. Assim, acredito que, por meio da publicidade, o mercado se reinventa. Vende-se tudo. Vendem-se fórmulas de beleza, saúde, de sucesso financeiro, afetivo e emocional.

A indústria da beleza, por exemplo, parece existir somente devido a uma alimentação permanente de sentimentos de imperfeição corporal e de inferioridade que procura atingir a todos. Ao observar os discursos que existem por trás da idéia de beleza feminina, percebe-se o quanto a questão mercadológica está presente. Observa-se na maquiagem, no cabeleireiro, nos sapatos, bolsas, cintos, roupas, perfumes e tudo aquilo que elas são, de certa maneira, induzidas a consumir com a promessa de parecerem mais bonitas. E isso muda todas as estações, obedecendo à dinâmica do mercado e da livre circulação do capital. Não só os acessórios, mas o próprio corpo entra nessa dinâmica da mudança e do mercado.

Há pouco mais de uma década, por exemplo, tinha-se a idéia de que mulheres com curvas e medidas corporais mais largas eram sexys. A atriz e modelo canadense, Pâmela Anderson, parece ter sido um dos ícones sexy symbol dessa geração. Atualmente, pode se ver que esse modelo mudou muito. Os corpos mais robustos, com elevado IMC (Índice de Massa Corporal) deram lugar à magreza. A magreza passou a ser um valor e o ideal de beleza vigente ${ }^{15}$. A modelo brasileira, Gisele Bundchen ${ }^{16}$ parece ter "roubado" a cena nos desfiles mundiais dos corpos contemporâneos.

\footnotetext{
${ }^{14}$ Um exemplo dessa "virada comportamental" é a idéia do novo conceito de homem, o homem "metrossexual"; um sujeito antenado com moda e beleza, frequentador de salões de beleza, de Shopping Centers e academias. O jogador de futebol inglês, David Beckham, parece ser um dos principais representantes desse novo conceito de homem contemporâneo, denominado metrossexual.

${ }^{15}$ Ao mesmo tempo em que o padrão de beleza atual, representado pela magreza, se afirma como modelo ideal de corpo, várias críticas surgem sobre a questão, pelo fato de violar o IMC (Índice de Massa Corpórea) aceitável e, consequentemente, prejudicar a saúde. As críticas se dão pelo fato da não observação do IMC - considerado normal pela Organização Mundial de Saúde mais ou menos em torno de 18,5. O IMC é calculado pelo peso (em quilos) dividido pela altura (em metros) ao quadrado. Por exemplo, alguém que pese $50 \mathrm{~kg}$ e tenha 1,50 de altura tem o IMC de 22,2.'

${ }_{16}$ Veja que o modelo de corpo e o padrão de beleza "Gisele Bundchen" encontram-se cada vez mais globalizados. Expande-se por todos os continentes. Hoje, nem mesmo o mundo oriental com sua cultura e tradições milenares escapam da influência desse padrão estético que nasceu no Ocidente.
} 


\section{CONSIDERAÇÕES FINAIS}

Talvez pensar a cultura contemporânea a partir do corpo não seja a forma ainda mais privilegiada. Pode ser que nem mesmo ofereça dados mais férteis do ponto de vista da literatura científica e bases mais densas que a religião, a política, a economia, a cultura, a comunicação ou o consumo. Mas acredito que tem um ponto significativo aí: o corpo parece ter "roubado" a cena do cenário contemporâneo. E foi sobre essa cena do espetáculo que se passa no mundo contemporâneo, que concentrei o meu olhar e relato aqui neste esboço teórico o qual sub-titulei de "cartografias da contemporaneidade".

De todo modo, considero que pensar a contemporaneidade através da corporeidade seja uma das formas manifestas e palpáveis de nosso tempo, pela natureza da própria cena do objeto que se impõe de imediato ao primeiro lançar de olhos. No entanto, cabe talvez uma interpretação mais precisa dessa cena. Pode ser que ela seja parte essencial do teatro no palco da existência humana e, entendê-la, ajudará em melhor compreensão da peça maior, a que aqui chamo de cultura contemporânea num sentido antropológico.

Portanto, o que parece ficar claro é que, a cultura contemporânea é uma cultura do corpo em evidência. E o corpo passa, atualmente, a ser uma instância que atrai olhares de todos os campos do saber, e assim, a se afirmar cada vez mais num espaço multidisciplinar. Dessa forma, parece já não ser mais possível abordá-lo e tratá-lo a partir do prisma de uma única disciplina ou de um campo específico do saber. O corpo em evidência hoje em dia, demonstra requerer as paisagens diversas da cultura contemporânea na sua constituição e representação atual. 


\section{REFERÊNCIAS}

BAUMAN, Zigmunt. Modernidade líquida. Rio e Janeiro: Jorge Zahar, 2001.

BAUMAN, Zigmunt. Vida Líquida. Rio de Janeiro: Zahar, 2007.

BAUMAN, Zigmunt. Globalização: as conseqüências humanas. Rio de Janeiro: Jorge Zahar, 1999.

CANCLINI, Néstor. Consumidores e cidadãos. Conflitos multiculturais da globalização. Rio de Janeiro: Editora da UFRJ, 1995.

COSTA, Jurandir Freire. O vestígio e a aura: corpo e consumismo na moral do espetáculo. Rio de Janeiro: Garamond, 2005.

COSTA, Jurandir Freire. A subjetividade exterior. Palestra proferida no Círculo Psicanalítico do Rio de Janeiro - Texto inédito. 2001. Disponível em:

<http://www.4shared.com/file/27678201/336489c/A subjetividade exterior Jurandir

Freire Costa.html?s=1>. Acesso em: 20 ago 2008.

DESCARTES, René. Discurso do método. São Paulo: Hemus, 1998.

DELEUZE, Gilles. Post-Scriptum - sobre as sociedades de controle. In: DELEUZE, Gilles. Conversações. São Paulo, SP: Editora 34, 1990.

DELEUZE, Gilles; GUATTARI, Félix. Mil Platôs - Capitalismo e Esquizofrenia. São Paulo: Editora 34, 1995.

DUNCAN, Zélia. Alma. Disponível em: <http://www.4shared.com/audio/0OQ7Rm /Zelia Duncan - Alma.html?s=1>. Acesso em: 20 de mai. 2010.

FUKUYAMA, Francis. Nosso futuro pós-humano: Conseqüências da revolução da biotecnologia. Rio de Janeiro: Roço, 2003.

GOFFMAN, Erving. Estigma: notas sobre a manipulação da identidade deteriorada. Rio de Janeiro: Guanabara, 1988. 
HALL, Stuart. A identidade cultural na pós-modernidade. Rio de Janeiro: DP\&A Editora, 2003.

KANT, Immanuel. Que é Esclarecimento? Petrópolis: Vozes, 1985.

KLEIN, Naomi. Sem Logo - A tirania das marcas em um planeta vendido. Rio de Janeiro: Ed. Record, 2006.

KHUN, Thomas. A estrutura das revoluções científicas. 4 ed. Tradução de Beatriz Vianna Boeira e Nelson Boeira. São Paulo: Editora Perspectiva, 1996.

LE BRETON, David. Adeus ao corpo: antropologia e sociedade. Campinas: Papirus, 2003.

LE BRETON, David. A sociologia do corpo. Petrópolis: Vozes, 2009.

LIPOVETSKY, Gilles. O Império do efêmero - a moda e seus destinos na sociedade moderna. São Paulo: Companhia das Letras, 1989.

LIPOVETSKY, Gilles. A era do vazio - ensaios sobre o individualismo contemporâneo. São Paulo: Manole, 2005.

LYOTARD, Jean-François. A condição pós-moderna. Lisboa: Gradativa, 1989.

SERRES, Michel. Hominescência: o começo de uma outra humanidade?. Rio de Janeiro: Bertrand Brasil, 2003.

SERRES, Michel. Filosofia Mestiça. Tradução Maria Ignez Duque Estrada. Rio de Janeiro: Nova Fronteira, 1992.

SIBILIA, Paula. O homem pós-orgânico: corpo, subjetividade e tecnologias digitais. Rio de Janeiro: Relume Dumará, 2002.

VILAÇA, Nízia; GÓES, Fred. Em Nome do Corpo. Rio de Janeiro: Artemídia; Rocco, 1998.

Artigo:

Recebido em: 22/04/2011

Aceito em: 13/06/2011 